\title{
Is there a flight to quality due to inflation uncertainty?
}

\author{
Bulent Guler ${ }^{\mathrm{a}}$, Umit Ozlale ${ }^{\mathrm{b}, *}$ \\ ${ }^{a}$ Department of Economics, Harkness Hall, University of Rochester, Rochester, NY 14627, USA \\ ${ }^{\mathrm{b}}$ Department of Economics, Bilkent University, Bilkent, Ankara 06800, Turkey
}

Received 8 March 2004

Available online 18 August 2004

\begin{abstract}
After two types of inflation uncertainty are derived within a time-varying parameter model with GARCH specification, the relationship between inflation uncertainty and interest rates for safe assets is investigated. The results support the existence of a "flight to quality" effect. (C) 2004 Elsevier B.V. All rights reserved.
\end{abstract}

Keywords: Kalman filter; Generalized auto-regressive conditional heteroskedasticity; Flight to quality effect

\section{Introduction}

Inflation uncertainty may affect interest rates for safer assets through two distinct channels. First, an increase in uncertainty will raise the interest rates by an increase in the inflation risk premium. Such a relationship is documented in several studies like Refs. [1-4]. On the other hand, there is another channel, "flight to quality", that has not been investigated previously in this context. According to that view, an increase in inflation uncertainty might lead to a perceived increase in economy-wide risk, prompting a "flight to quality" by investors, in which their

\footnotetext{
*Corresponding author. Tel.: + 90-312-290-1584; fax: +90-312-266-5140.

E-mail address: ozlale@bilkent.edu.tr (U. Ozlale).
} 
demand for safe assets like treasury bills rises. This increase in demand for these assets would tend to lower the associated interest rates. Therefore, a negative relation between inflation uncertainty and interest rates for safe assets may also exist.

This study takes the above discussion as its starting point and investigates the validity of these two different channels for the United States economy. Apart from the studies that have dominated the literature, inflation uncertainty is modelled in a time-varying parameter framework with GARCH specification. Such a methodology is originally introduced by Evans (1991) [5] and can be used to identify several types of inflation uncertainties: Uncertainty can either emerge from the randomness in the structure of inflation process, that we name as "structural uncertainty", or it can be generated by the shocks that hit the economy, which we name as "impulse uncertainty". The effects of these two distinct types of uncertainties on safe assets can vary significantly.

We find that while structural uncertainty effects treasury bills positively as expected, impulse uncertainty generates a "flight to quality" effect and it is negatively associated with safe interest rates. The following section introduces the methodology to model inflation uncertainty. Next, estimation results are presented. The last section concludes.

\section{Modelling inflation uncertainty}

Consistent with Ref. [5], we employ a time-varying parameter model with GARCH specification. Formally,

$$
\begin{aligned}
& \pi_{t+1}=X_{t} \beta_{t+1}+e_{t+1}, \text { where } e_{t+1} N\left(0, h_{t}\right), \\
& \beta_{t+1}=\beta_{t}+V_{t+1}, \text { where } V_{t+1} N(0, Q), \\
& h_{t}=h+\sum_{i=0}^{m} \phi_{i} e_{t-i}^{2}+\sum_{i=1}^{n} \gamma_{i} h_{t-i},
\end{aligned}
$$

where $X_{t}$ is a vector of explanatory variables for inflation, known at time $t$. Lagged values of inflation are used in the regressor matrix. $\beta_{t+1}$ is a vector of parameters, $e_{t+1}$ is the shock to inflation that cannot be forecasted with information at time $t$. It is normally distributed with a time-varying conditional variance of $h_{t}$, which indicates the changes in uncertainty of the future inflation at time $t$ and it is specified as a linear function of current and past squared forecast errors. Finally, $\phi_{i}$ and $\gamma_{i}$ are the time-varying parameters of $h_{t}$. In this modelling, Eqs. (1) and (3) represent a generic ARCH specification of inflation, while Eq. (2) represents the change in the dynamics of the inflation process over time. 
Next, we should include the Kalman filter updating equations:

$$
\begin{aligned}
& \pi_{t+1}=X_{t} E_{t} \beta_{t+1}+\eta_{t+1}, \\
& H_{t}=X_{t} \Omega_{t+1 \mid t} X_{t}^{T}+h_{t}, \\
& E_{t+1} \beta_{t+2}=E_{t} \beta_{t+1}+\left[\Omega_{t+1 \mid t} X_{t}^{T} H_{t}^{-1}\right] \eta_{t+1}, \\
& \Omega_{t+2 \mid t+1}=\left[I-\Omega_{t+1 \mid t} X_{t}^{T} H_{t}^{-1} X_{t}\right] \Omega_{t+1 \mid t}+Q,
\end{aligned}
$$

where $\Omega_{t+1 \mid t}$ stands for the conditional covariance matrix of $\beta_{t+1}$, which represents uncertainty about the structure of the inflation process. The conditional variance of inflation $H_{t}$ depends upon both $h_{t}$ and the conditional variance of $X_{t} \beta_{t+1}$, which is $X_{t} \Omega_{t+1 \mid t} X_{t}^{T}$, formulated in Eq. (5). Therefore, two types of inflation uncertainties, which govern the conditional variation in inflation, emerge: We can refer to inflation uncertainty associated with randomness in $\beta$ as "structural uncertainty", which is denoted by $X_{t} \Omega_{t+1 \mid t} X_{t}^{T}$; while uncertainty associated with the randomness in " $e$ " is called "impulse uncertainty" and it is represented by the conditional variance of $e_{t+1}$, which is $h_{t}$. In other words, "e" can be viewed as describing the shocks that hit the economy. Then, the time varying parameter $\beta$ will show how these shocks are propagated through the economy. Such a terminology leads us to Frisch and Slutsky's distinction between impulses and propagation.

The model is justified both in theoretical and empirical grounds in Ref. [5]. However, it may be useful to mention the theoretical justification about assuming a random walk about the evolution of parameters: Since changes in monetary policy, which would be difficult to predict, lead to structural variations in inflation, it is convenient to assume that $E_{t} \beta_{t+1}=E_{t} \beta_{t}$.

\section{Results}

We employ monthly US data from 1953:01 to 2002:11. Inflation series is obtained by using consumer price index (CPI). Structural and impulse uncertainties are derived using Eqs. (1) through (7). The optimal number of lags for the regressor matrix in Eq. (1) is chosen according to Akaike and Schwarz information criteria. Initially, three months effective treasury bill rate is regressed on structural and impulse uncertainties. Since effective rates are used, expected inflation does not appear on the right hand side. The results can be seen in the first row of Table 1 . While structural uncertainty affects the interest rate positively, impulse uncertainty moves the rates in the opposite direction. Moreover, when secondary market treasury bill rates of same maturity is used, the results remained robust as it can be seen in the second row of Table 1. Such a finding implies that structural uncertainty increases interest rates, possibly through an increase in the inflation risk premium. However, the negative impact of impulse uncertainty on the interest rates is an evidence for "flight to quality": an increase in impulse uncertainty occurs mostly because the economy gets hit by a series of shocks, increasing the economy-wide risk 
Table 1

Estimation results

\begin{tabular}{llll}
\hline & Constant & $\begin{array}{l}\text { Structural } \\
\text { uncertainty }\end{array}$ & $\begin{array}{l}\text { Impulse } \\
\text { uncertainty }\end{array}$ \\
\hline Treasury bill & $1.059212(547.2715)$ & $0.000510(-2.965591)$ & $-0.000674(-2.929100)$ \\
$\begin{array}{l}\text { Secondary market } \\
\text { Treasury Bill }\end{array}$ & $\begin{array}{l}1.052955 \\
(578.0073)\end{array}$ & $\begin{array}{l}0.000597 \\
(-3.685392)\end{array}$ & -0.000779 \\
AAA-treasury & $0.016965(20.98814)$ & $-0.000606(-8.436335)$ & $0.000751(7.812959)$ \\
BAA-treasurysec & $0.031898(32.31313)$ & $-0.000764(-8.699619)$ & $0.000966(8.222303)$ \\
BAA-treasury & $0.025642(28.51066)$ & $-0.000677(-8.465972)$ & $0.000861(8.046029)$ \\
AAA-treasurysec & $0.023222(26.81198)$ & $-0.000693(-8.997980)$ & $0.000856(8.308233)$ \\
\hline
\end{tabular}

Note: $t$-statistics are reported in the parentheses.

and prompting a "flight to quality" by investors, in which their demand for safer assets such as treasury bill rises, which, in turn, lowers their interest rates.

Finally, for robustness purposes, we regressed the spread between corporate bonds (both AAA and BAA type of same maturity) and treasury bill rates on structural and impulse uncertainties. Those types of bonds would presumably be viewed more risky, so if the explanation works, their interest rates would rise with an increase in impulse uncertainty, which would increase the spread between the two variables. The results are displayed in the last four rows of Table 1. They imply that "flight to quality" effect persists and increases the spread between riskier and safer assets. Another interesting finding is that the impact of structural uncertainty on treasury bills is larger than its impact on corporate bonds.

\section{Conclusion}

There are two distinct channels through which inflation uncertainty may affect interest rates for safer assets like treasury bills. First, an increase in inflation risk associated with higher uncertainty is expected to increase interest rates. Second, an increase in uncertainty, which could also be viewed as a rise in economy-wide risk, might generate a "flight to quality" effect and increase the demand for safer assets, which, in turn decreases their interest rates.

In this paper, we explored the validity of these two channels after decomposing inflation uncertainty into two parts, namely structural and impulse uncertainty, consistent with the methodology in Ref. [5]. We find that while structural uncertainty supports the first channel and increases the interest rates for treasury bills, impulse uncertainty generates a "flight to quality effect" and decreases their interest rates. 
Moreover, the implications remained robust when spreads between riskier corporate bonds and treasury bills are used.

\section{Acknowledgements}

We are grateful to $M$. Evans and Peter N. Ireland for their kind help and suggestions. The usual disclaimer applies.

\section{References}

[1] F.S. Mishkin, The real interest rate: an empirical investigation, Carnegie-Rochester Conf. Ser. Public Policy 15 (1981) 151-200.

[2] E. Fama, M. Gibbons, Inflation, real returns and capital investment, J. Monetary Econ. 9 (1982) 297-323.

[3] L.K.C. Chan, Consumption, inflation risk, and interest rates: an empirical analysis, J. Bus. 67 (1994) 69-96.

[4] H. Berument, The impact of inflation uncertainty of interest rates in the UK, Scottish J. Polit. Econ. 46 (1999) 207-218.

[5] M. Evans, Discovering the links between inflation rates and inflation uncertainty, J. Money Credit Banking 23 (1991) 169-184. 